\title{
Drugs that Target p53-Mdm2 Interaction
}

\author{
Monde Ntwasa* \\ Department of Life \& Consumer Sciences Cnr, Pioneer and Christiaan de Wet Roads B2-010 Calabash Building, University of \\ South Africa, South Africa
}

*Corresponding author: Monde Ntwasa, Department of Life \& Consumer Sciences Cnr, Pioneer and Christiaan de Wet Roads B2-

010 Calabash Building, University of South Africa, Florida, Johannesburg, 1710, South Africa

\begin{tabular}{|c|c|}
\hline ARTICLE INFO & ABSTRACT \\
\hline & $\begin{array}{l}\text { Citation: Monde Ntwasa. Drugs that Target p53-Mdm2 Interaction. Biomed J Sci \& Tech } \\
\text { Res 37(4)-2021. BJSTR. MS.ID.006025. }\end{array}$ \\
\hline Published: 慧 July 28, 2021 & \\
\hline
\end{tabular}

\section{Introduction}

The first identified tumor suppressor, p53, is the guardian of the genome and is tightly controlled by its master negative regulator, mouse double minute (Mdm2), and its paralogues $\mathrm{Mdm} 4$ and HDMX [1]. p53 is regulated by a negative feedback loop whereby p53 transcriptionally activates Mdm2. In turn, Mdm2 catalyzes the ubiquitination and proteasomal degradation of p53. Virtually all cancers have dysfunctional p53 due to either the gene's mutation or to dysregulated p53 signaling in the background of wild-type p53. The most common mechanism by which p53 signaling is dysregulated is the overexpression of Mdm2. Its overexpression occurs in tumors either due to gene amplification or by increased transcription and or translation. However, it is unusual for Mdm2 overexpression to be combined with mutated p53 in the same tumor. Consequently, targeting the p53-Mdm2 interaction has become a desirable approach to developing small molecule anticancer drugs.

\section{Mechanism of Action}

Inhibitors that reactivate the function of p53 act by binding to the Mdm2 p53 binding domain, thereby restoring p53 function inducing cell cycle arrest and apoptosis. This inhibition of Mdm2-p53 binding leads to non-genotoxic p53 stabilization, cell cycle arrest, and apoptosis and is associated with p21WAF1 protein and caspase-3/7 activity [2]. This finding suggests that Mdm2 inhibitors will only function in a p53 wild-type context. The original lead molecule was a p53 peptide that bound snuggly into the hydrophobic pocket in Mdm2 and led to the nutlin 3a, a firstgeneration molecule capable of reactivating p53 function. Nutlin 3a, now known as idasanutlin, as a second-generation molecule, has reached the phase III clinical stages for refractory or relapsed acute myeloid leukaemia when combined with cytarabine [3-5]. Other second-generation molecules currently under development are listed in Table 1 and are many in the first phase of clinical trials [6-9].

Table 1.

\begin{tabular}{|c|c|c|c|c|}
\hline Small molecule & Developer & Stage & cancer & Reference \\
\hline AMG232 & Amgen & Phase $1 \mathrm{~b}$ & relapsed/refractory acute myeloid leukemia & $(4)$ \\
\hline CGM097 & Novartis & Phase 1 & Solid tumours with wt p53 & $(5,6)$ \\
\hline HDM201 & Novartis & Phase $1 \mathrm{~b}$ & Translational modelling, metastatic liposarcoma & $(7,8)$ \\
\hline SAR405838 & Sanofi & Phase 1 & Solid tumours, & $(9,10)$ \\
\hline MK-8242 & & Phase 1 & $\begin{array}{l}\text { Advanced solid tumours and refractory/recurrent } \\
\text { acute myelogenous leukemia }\end{array}$ & $(11,12)$ \\
\hline DS-3032b & $\begin{array}{l}\text { Daiichi } \\
\text { Sankyo }\end{array}$ & Phase 1 & Liposarcoma, solid tumours, lymphomas & $(13)$ \\
\hline
\end{tabular}




\section{Prospects and Limitations of the Strategy}

Pre-clinical and clinical trial data show that these Mdm2 inhibitors are well tolerated and can inhibit Hdmx [10-12]. There are better prospects when these drugs are combined with chemotherapy, radiation, or other small molecules [13]. One limitation to using Mdm2 inhibitors is that they ideally compensate for upstream defects in the p53 signaling but may not be effective if there are defects in downstream elements of the pathway. Another shortcoming is that $\mathrm{Mdm} 2$ is not the only negative regulator of p53. Indeed there are many negative regulators of p53 [14]. The most critical threat to the development of these drugs is the demonstrated emergence of stable drug resistance, at least in cell culture. In cell culture, these drugs tend to cause cell cycle arrest and little apoptosis. Furthermore, MCF- 7 and U-2 OS cells recovered after the removal of idasanutlin from the culture medium and in de novo generation of p53 mutations was detected in U-2 OS cells after prolonged culture.

\section{Possible Interventions}

One of the possible interventions could be the combination of targeted therapies with radiation or with chemotherapy. Pre-clinical studies show that a combination of nutlin $3 a$ and chemotherapy produced additive and synergistic outcomes in cell culture dependent on the effective dose applied (2). The combination therapy with inhibitors of select negative regulators of p53 may be another approach to improve the effectiveness of these drugs. One such is the retinoblastoma binding protein 6 (RBBP6). Like Mdm2 -/- mice, RBBP6 null mutants are embryonic lethal and can be rescued by simultaneous deletion of p53 [15]. Furthermore, this study shows that RBBP6 enhances Mdm2 catalytic activity. Moreover, the RBBP6 Drosophila homolog SNAMA is also embryonic lethal, underscoring that this gene is essential through evolution. Moreover, there has been no Mdm2 homologue found in the fly, and it has been declared that it does not exist [16]. These studies indicate that RBBP6 on its own may accomplish Mdm2 functions in some contexts and that targeting both Mdm2 and RBBP6 is a desirable approach because they are intimately involved in regulating $\mathrm{p} 53$. Other potential inhibitors of p53-Mdm2 interactions are those that target the E3 ligase activity. These have, however, proved to be ineffective.

\section{Conclusion}

Although this class of compounds has produced promising results in early-stage clinical studies, the critical concern is the possible haematological toxicity. However, the poor effectiveness of these compounds individually to induce apoptosis in cancer cells is also of great concern. Current studies indicate that combination therapy could mitigate these shortcomings.

\section{References}

1. Momand J, Villegas A, Belyi VA (2011) The evolution of MDM2 family genes. Gene 486(1-2): 23-30.

2. Zanjirband M, Edmonson RJ, Lunec J (2016) Pre-clinical efficay and synerhistic potential of the Mdm2-p53 anatagonists, Nutlin-3 and RG7388, as single agents and in combined treatment with cisplatinin ovarian cancer. Oncotarget 7(26): 40115-40134.

3. Montesinos P, Beckermann BM, Catalani O, Esteve J, Gamel K, et al. (2020) MIRROS: a randomized, placebo-controlled, Phase III trial of cytarabine \pm idasanutlin in relapsed or refractory acute myeloid leukemia. Future Oncol 16(13): 807-815.

4. Erba HP, Becker PS, Shami PJ, Grunwald MR, Flesher DL, et al. (2019) Phase 1b study of the MDM2 inhibitor AMG 232 with or without trametinib in relapsed/refractory acute myeloid leukemia. Blood Advances 3(13): 1939-1949.

5. Holzer $P$, Chène $P$, Ferretti $S$, Furet $P$, Gabriel T, et al. (2016) Abstract 4855: Discovery of NVP-HDM201 - First disclosure of a Next-Generation Mdm2 inhibitor with superior characteristics. Cancer Res 76(14): 4855.

6. Hyman DM, Chatterjee M, Vos Fd, Lin C-C, Suárez C, et al. (2017) Abstract CT150: Optimizing the therapeutic index of HDM2 inhibition: Results from a dose- and regimen-finding Phase I study of NVP-HDM201 in pts with \&lt;em\&gt;TP53\&lt;/em\&gt; wt advanced tumors. Cancer Res 77(13): CT150.

7. Guerreiro N, Jullion A, Ferretti S, Fabre C, Meille C (2021) Translational modeling of anticancer efficacy to predict clinical outcomes in a first-inhuman Phase 1 study of MDM2 Inhibitor HDM201. The AAPS Journal 23(2): 28.

8. Razak AA, Bauer S, Blay J-Y, Quek R, Suárez C, et al. (2018) Abstract CT009: Results of a dose- and regimen-finding Phase Ib study of HDM201 in combination with ribociclib in patients with locally advanced or metastatic liposarcoma. Cancer Res 78(13): CT009.

9. De Jonge M, De Weger VA, Dickson MA, Langenberg M, Le Cesne A, et al. (2017) A phase I study of SAR405838, a novel human double minute 2 (HDM2) antagonist, in patients with solid tumours. Eur J Cancer 76: 144-151.

10. De Weger VA, De Jonge M, Langenberg MHG, Schellens JHM, Lolkema M, et al. (2019) A phase I study of the HDM2 antagonist SAR405838 combined with the MEK inhibitor pimasertib in patients with advanced solid tumours. Br J Cancer 120(3): 286-293.

11. Wagner AJ, Banerji U, Mahipal A, Somaiah N, Hirsch H, et al. (2017) Phase I Trial of the Human Double Minute 2 inhibitor MK-8242 in patients with advanced solid tumors. Journal of clinical oncology: official journal of the American Society of Clinical Oncology 35(12): 1304-1311.

12. Ravandi F, Gojo I, Patnaik MM, Minden MD, Kantarjian H, et al. (2016) A phase I trial of the human double minute 2 inhibitor (MK-8242) in patients with refractory/recurrent acute myelogenous leukemia (AML). Leuk Res 48: 92-100.

13. Bauer TM, Gounder MM, Weise AM, Schwartz GK, Carvajal RD, et al. (2018) A phase 1 study of MDM2 inhibitor DS-3032b in patients with well/de-differentiated liposarcoma (WD/DD LPS), solid tumors (ST) and lymphomas (L). J Clin Oncol 36(15): 11514.

14. Ntwasa M (2015) Cancer Drugs Targeting the p53 Regulatory Machinery. In: Atta-ur-Rahman F, Choudhary MI, (Eds.)., Frontiers in Anti-Cancer Drug Discovery: Bentham Publishers, pp. 199-230.

15. Li L, Deng B, Xing G, Teng Y, Tian C, et al. (2007) PACT is a negative regulator of p53 and essential for cell growth and embryonic development. Proc Natl Acad Sci USA 104(19): 7951-7956.

16. Lane DP, Cheok CF, Brown C, Madhumalar A, Ghadessy FJ, et al. (2010) Mdm2 and p53 are highly conserved from placozoans to man. Cell Cycle 9(3): 540-547. 
ISSN: 2574-1241

DOI: 10.26717/BJSTR.2021.37.006025

Monde Ntwasa. Biomed J Sci \& Tech Res

(C) (P) This work is licensed under Creative BY Commons Attribution 4.0 License

Submission Link: https://biomedres.us/submit-manuscript.php

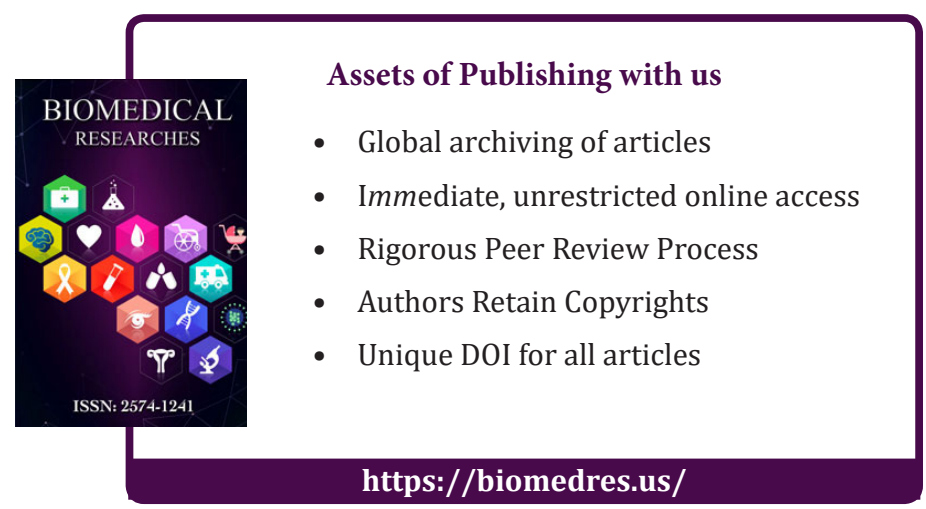

